\title{
Bubble, bubble, toil and trouble?
}

\author{
Patrick T. Roughneen, MD, and Abe DeAnda, Jr, MD
}

\footnotetext{
From the Division of Cardiothoracic Surgery, Department of Surgery, University of Texas Medical Branch, Galveston, Tex.

Disclosures: Authors have nothing to disclose with regard to commercial support.

Received for publication April 19, 2016; accepted for publication April 20, 2016; available ahead of print May 26, 2016.

Address for reprints: Abe DeAnda, Jr, MD, Division of Cardiothoracic Surgery, Department of Surgery, University of Texas Medical Branch, 301 University Blvd, Galveston, TX 77555 (E-mail: ptroughn@utmb.edu).

J Thorac Cardiovasc Surg 2016;152:1410-1

$0022-5223 / \$ 36.00$

Copyright (C) 2016 by The American Association for Thoracic Surgery

http://dx.doi.org/10.1016/j.jtcvs.2016.04.088
}

Spinal cord injury after surgery of the thoracoabdominal aorta is a devastating complication for both the patient and the surgeon. Various adjuncts and preventive measures have been developed to lower the risk of paraplegia (paraparesis). Despite these efforts, however, spinal cord injury still occurs in $2 \%$ to $15 \%$ of patients undergoing surgery, either open and endovascular, of the thoracic aorta. In this issue of The Journal, Kanda and colleagues ${ }^{1}$ provide an intriguing and significant contribution to understanding and ameliorating mechanisms that lead to spinal cord injury. In their experimental rabbit model, they have provided preliminary evidence that infusion of artificial cerebrospinal fluid (CSF), with or without nanobubble oxygenation, may ameliorate spinal cord injury as assessed according to spinal cord histologic and Tarlov score analyses. The study of Kanda and colleagues ${ }^{1}$ has some inherent weaknesses in terms of the number of animals studied and the relatively short period (15 minutes) during which infrarenal aortic clamping was performed; adjustment of these factors might have strengthened the scientific evidence to support their hypothesis.

In addition to providing some evidence to support the hypothesis of Kanda and colleagues, ${ }^{1}$ the data presented raise unanswered questions that may provide further insight into preventing this devastating complication. The histologic data from L2 and L3 large motor neuron count demonstrate significant differences between the control group (group C) and both the oxygen-supplemented (group $\mathrm{O})$ and the non-oxygen supplemented control (group $\mathrm{N}$ ) groups; however, no significant difference between groups $\mathrm{O}$ and $\mathrm{N}$, contrary to their original hypothesis. This trend was also noted in the Tarlov score data, with significant differences noted only between groups $\mathrm{O}$ and $\mathrm{C}$ but not between groups $\mathrm{O}$ and $\mathrm{N}$. If, as Kanda and colleagues ${ }^{1}$ hypothesized, oxygen were truly protective, differences should have been noted in viable L2 and L3 large motor neuron count and Tarlov score between groups $\mathrm{O}$ and $\mathrm{N}$. This was not the case.

The oxygen consumption data before and after induction of spinal ischemia provided in Figure 2 of Kanda and colleagues $^{1}$ also provide evidence to suggest that factors

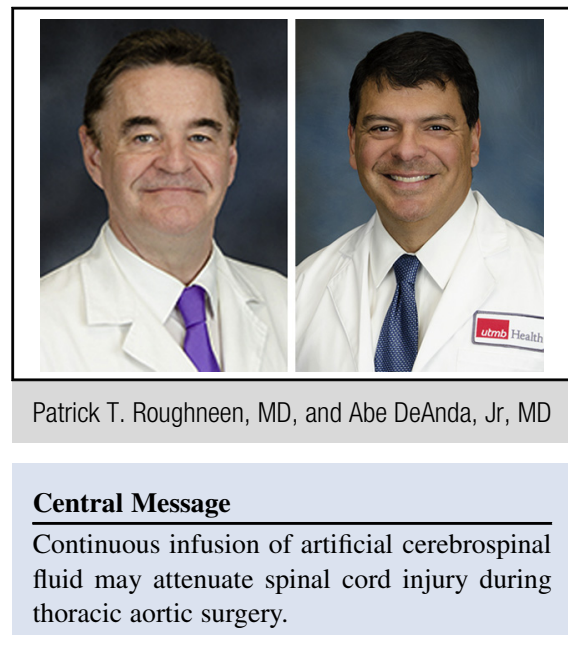

See Article page 1401.

other than oxygen alone are important. During continued infusion of nonoxygenated artificial CSF (group N), ischemic spinal cord tissue did not significantly extract oxygen relative to the preischemic state; however, the absence of oxygenated artificial CSF infusion (group C) did result in a significant difference in oxygen concentrations when spinal ischemia was induced $(P<.01)$. It appears that the infusion of artificial CSF during spinal ischemia affects the degree to which oxygen is extracted by the ischemic spinal cord tissue.

Interpreting the unexplained lack of significant difference in neurologic data between groups $\mathrm{O}$ and $\mathrm{N}$ and the oxygen extraction data among groups $\mathrm{C}, \mathrm{N}$, and $\mathrm{O}$ leads us to believe that oxygen itself is not the only factor that has produced these results. What also appears to be important is the "clearance" effect or dilution of deleterious factors by continual artificial CSF infusion present in both groups $\mathrm{O}$ and $\mathrm{N}$. Alternatively, factors other than oxygen in the artificial CSF (for example glucose), to which both groups $\mathrm{O}$ and $\mathrm{N}$ were subjected, may be responsible for the superior neuroprotection seen in both groups relative to group $\mathrm{C}$. The artificial CSF used in groups $\mathrm{N}$ and $\mathrm{O}$ needs to be carefully analyzed in comparison with CSF directly extracted from the rabbit model to determine any significant differences in their constitution.

Kanda and colleagues ${ }^{1}$ also observed a neuroprotective effect in both experimental groups $\mathrm{O}$ and $\mathrm{N}$ with respect to group $\mathrm{C}$, despite doubling of the CSF pressure before and after the modulation of spinal ischemia. This is contrary to the widely held concept that CSF drainage is itself neuroprotective. ${ }^{2}$ The data provided in Figures 3, 4, and 5 
of Kanda and colleagues ${ }^{1}$ demonstrates that both groups $\mathrm{N}$ and $\mathrm{O}$, with a mean CSF pressure of $20 \mathrm{~mm} \mathrm{Hg}$, had significantly better neuroprotection than the control group, group C, with a mean CSF pressure of $10 \mathrm{~mm} \mathrm{Hg}$.

On the basis of these observations, it is clear that further experimental work is required to determine whether the continual artificial CSF infusion during spinal cord ischemia is in itself neuroprotective. Whether this effect is attenuated or enhanced by concomitant CSF drainage remains to be seen, as does whether oxygenation itself or other factors in artificial CSF are neuroprotective during spinal cord ischemia.

The scientific work provided by Kanda and colleagues ${ }^{1}$ advances the concept that cytoprotection of ischemic tissue may potentially be achieved by mechanisms of enhanced oxygenation and infusion washout of the ischemic tissue. The development of neuroprotective infusion therapy from such research might be fruitful in preventing the devastating complication of paraplegia that we too frequently see in surgery of the thoracic aorta. Importantly, it may also have broader implications in cardiothoracic surgery for the enhancement of cardioplegia and heart preservation in transplantation.

\section{References}

1. Kanda K, Adachi O, Kawatsu S, Sakatsume K, Kumagai K, Kawamoto S, et al Oxygenation of the cerebrospinal fluid with artificial cerebrospinal fluid can ameliorate a spinal cord ischemic injury in a rabbit model. J Thorac Cardiovasc Surg. 2016;152:1401-9.

2. Kulik A, Castner CF, Kouchoukos NT. Outcomes after thoracoabdominal aortic aneurysm repair with hypothermia circulatory arrest. J Thorac Cardiovasc Surg. 2011;141:953-60 